\title{
SIMULATION AND MEASUREMENT OF \\ ROAD TUNNEL VENTILATION
}

\author{
Axel Bring ${ }^{1}$, Tor-Göran Malmström¹ ${ }^{1}$ Carl Axel Boman² \\ KTH, Stockholm, Sweden
}

\begin{abstract}
A computer program for PC has been prepared to simplify studies of air flows in road tunnels and the related problem of pollution concentration due to emission from vehicles . Results from simulations include, air pressures, flow rates, and pollution concentrations along the tunnel. Input data are tunnel geometry, including flow friction factors and loss coefficients, plus traffic and emission data and air pressures at boundaries.
\end{abstract}

The program has been prepared in the IDA environment for modular simulation. All mathematical models have been formulated in the Neutral Model Format (NMF) [Sahlin 1994].

The program has been validated by comparisons with older programs [Malmström 1980]. Advantages of the new program, compared to traditional programs, are its great flexibility, maintainability and extendibility, plus the very moderate implementation time. It has proved to be a useful tool for studying alternative ventilation concepts for road tunnels.

Measurements have been made of air flow rates in part of the "Söderledstunneln", a much used road tunnel in central Stockholm. The measurements were made with tracer gas technique, which made it possible to measure without desturbing the traffic flow through the tunnel. The measurements have been compared to simulations of the air flow.

\section{Introduction}

The exhaust gases from cars and lorries make ventilation necessary for road tunnels. Many different systems have been used, ranging from full transverse ventilation, i.e. ventilation air is supplied and exhausted via terminal devices distributed along the tunnel, to longitudinal ventilation, which in oneway tunnels takes full advantage of the air flow induced by the traffic. The flow situation can be complicated; an example is two adjacent, interconnected, longitudinally ventilated one-way traffic tunnels. The need for computer modeling is obvious.

There are many design issues, first of all the choice between the basic ventilation layouts. Obvious variables are geographical/geological features, amount and type of traffic, fire safety, reliability, maintenance, and economical aspects. Special attention is often paid to environmental considerations such as air quality near tunnel openings, possibly resulting in demand of stack exhausts.

There is still some lack of detailed knowledge about the air flow physics in road tunnels. Compared to normal duct or pipe flow, the flow in a tunnel is influenced by the moving traffic, changing the air

\footnotetext{
${ }^{1}$ Dept of Building Services Engineering

Royal Institute of Technology

S-100 44 STOCKHOLM, SWEDEN

phone: +46-8-411 3238 , fax: +46-8-411 8432

e-mail: abring or tgm@ce.kth.se

${ }^{2}$ Pentiaq AB

P.O. Box 7

S-811 02 GÄVLE, SWEDEN

phone: +46-26-14 77 50, fax: +46-26-10 8801

email: boman@bmg.kth.se
} 
velocity profiles. In spite of this, normal pipe/duct procedures are used to calculate air flows in tunnels. The models used in this program are also to some extent based on duct flow models [Pursall \& West 1976 and 1979, PIARC 1991].

Other examples of areas with limited knowledge are the efficiency of different locations of momentum jet fans (the distance between them, location relative to ceiling and walls) and the pressure re-gain when part of the tunnel air is exhausted [Kawamura et al 1973].

The described situation emphazises the need for full scale tests. It is, however, difficult to measure the air flow rate in tunnels, due to the large dimensions and flow rates, and due to traffic. Tracer gas measurement is a possibility and such tests have been performed in a one $\mathrm{km}$ long tunnel section with longitudinal ventilation.

\section{The simulation program}

\subsection{Modular simulation}

During the last decade, modular - sometimes called object oriented - simulation environments have started to emerge. The primary aims of this development are to avoid the rigidity of many earlier monolithic programs and to facilitate exchange and reuse of component models; the models are regarded as data in the new tools.

One such environment is IDA [Sahlin \& Bring 1991], developed as a joint effort by the Division of Building Engineering Services at KTH (Royal Institute of Technology), Stockholm, and the Swedish Institute of Applied Mathematics.

At the heart of IDA lies a general solver for modular, differential-algebraic systems of equations. Key features of IDA are:

- Modelling (in NMF) is input/output free, i.e. variables have no irrevocable roles as given or calculated. Input/output free modelling naturally leads to models described by equations rather than the traditional calculation procedures, thus getting closer to the physical relationships known to the modeller.

- $\quad$ The system can handle algebraic as well as differential equations, including algebraic loops.

- $\quad$ The integration of dynamical systems uses variable timestep and order, for efficiency and for consistent, easy to use, accuracy control.

- Sparseness in the system of equations is utilized effectively, using a variety of algorithms.

- $\quad$ Models can be precompiled and distributed as ready building blocks.

- Discontinuities in driving functions and in model equations are handled properly.

- Extensions to the basic equation modelling allow handling of discrete system states, as required by e.g. hysteresis.

\subsection{Calculation of air flow}

The program uses lumped parameter models; i.e. in each tunnel section only the average air speed is modeled. Only steady state solutions are calculated, disregarding dynamics of pollution concentrations.

The air flow in any section of the tunnel system is derived from balances of air mass flow and total pressure for the whole tunnel.The steady flow energy equation is the basis for the calculations and the energy losses (or gains) are modeled similarly to normal pipe flow calculations. 
The loss coefficients are in some cases calculated by the program, but can also be given by the program user. The present lack of detailed knowledge for some of the air flow configurations precludes a completely automatic calculation of loss coefficients.

\subsubsection{Undivided sections}

In an undivided tunnel section, the total pressure change can be calculated by adding contributions from friction and area changes in the tunnel, vehicle piston effect, jet fans, and stack effect:

$$
\Delta \mathrm{P}_{\text {tot }}=-\Delta \mathrm{P}_{\text {frict }}-\Delta \mathrm{P}_{\text {area }}+\Delta \mathrm{P}_{\text {veh }}+\Delta \mathrm{P}_{\text {fan }}-\Delta \mathrm{P}_{\text {stack }}
$$

The different contributitions are

$$
\Delta \mathrm{P}_{\text {frict }}=\frac{\rho}{2} \sum_{\mathrm{i}} \lambda \frac{1_{\mathrm{i}}}{\mathrm{d}_{\mathrm{i}}} * \operatorname{Vair}_{\mathrm{i}} *\left|\operatorname{Vair}_{\mathrm{i}}\right|
$$

where

$\rho=$ density of air $\left(\mathrm{kg} / \mathrm{m}^{3}\right)$

$\lambda=$ friction factor

$l_{\mathrm{i}}=$ length of tunnel segment $\mathrm{i}$

$\mathrm{d}_{\mathrm{i}}=$ hydraulic diameter of tunnel segment $\mathrm{i}$

Vair $_{\mathrm{i}}=$ mean air velocity in segment $\mathrm{i}(\mathrm{m} / \mathrm{s})$

$\Delta \mathrm{P}_{\text {area }}=\frac{\rho}{2} \sum_{\mathrm{j}} \zeta_{\mathrm{j}} * \operatorname{Vair}_{\mathrm{j}} *\left|\operatorname{Vair}_{\mathrm{j}}\right|$

$\zeta_{\mathrm{j}}=$ resistance factors for area changes, depending on areas, shape of transition, and direction of flow

$$
\Delta \mathrm{P}_{\text {veh }}=\frac{\rho}{2} \sum_{\mathrm{k}} \mathrm{c}_{\mathrm{d}} * \frac{\mathrm{A}_{\mathrm{d}}}{\mathrm{A}_{\text {tun }}} * \mathrm{f}_{\mathrm{d}} *\left(\mathrm{Vveh}_{\mathrm{k}}-\mathrm{Vair}_{\mathrm{k}}\right) *\left|\mathrm{Vveh}_{\mathrm{k}}-\mathrm{Vair}_{\mathrm{k}}\right|
$$

$c_{d}=$ drag coefficient, depending on vehicle type

$\mathrm{A}_{\mathrm{d}}=$ vehicle cross section area $\left(\mathrm{m}^{2}\right)$

$\mathrm{A}_{\text {tun }}=$ tunnel area $\left(\mathrm{m}^{2}\right)$

$\mathrm{f}_{\mathrm{d}}=$ factor $>1$ correcting the drag coefficient for the tunnel effects

$\mathrm{Vveh}_{\mathrm{k}}=$ vehicle velocity $(\mathrm{m} / \mathrm{s})$ for vehicle $\mathrm{k}$

$\Delta \mathrm{P}_{\text {fan }}=\rho \sum_{\mathrm{m}} \mathrm{k}_{\text {fan }} *\left(\operatorname{Vfan}_{\mathrm{m}}-\operatorname{Vair}_{\mathrm{m}}\right) *\left|\operatorname{Vfan}_{\mathrm{m}}\right|$

$\mathrm{k}_{\text {fan }}=$ efficiency factor for the fan

$\operatorname{Vfan}_{\mathrm{m}}=$ fan outlet velocity $(\mathrm{m} / \mathrm{s})$ for fan $\mathrm{m}$

$\Delta \mathrm{P}_{\text {stack }}=\rho * \Delta \mathrm{Z} * \mathrm{~g}$

$\Delta \mathrm{z}=$ change of altitude in segment (m)

$\mathrm{g}=$ acceleration of gravity $\left(\mathrm{m} / \mathrm{s}^{2}\right)$. 


\subsubsection{Ventilation shafts}

In transverse and semi-transverse systems, air is often supplied into the tunnel without any velocity in the flow direction in order to produce good mixing. Consequently, the air has to be accelerated and causes a pressure drop in the flow direction. On the other hand, when air is exhausted, it will cause a pressure gain, especially if the exhausted part of the tunnel air initially has low momentum in the longitudinal direction.

The extra pressure loss (or gain) is modeled by

$\Delta \mathrm{P}_{\text {shaft }}=\frac{\rho}{2} \mathrm{k}_{\text {shaft }} * \mathrm{Vair}_{\max }^{2}$

where

$\mathrm{k}_{\text {shaft }}=$ loss coefficient

Vair $_{\max }=$ highest air velocity, before or after shaft $(\mathrm{m} / \mathrm{s})$

A frequent approximation is that the exhausted air has mean velocity in the flow direction. The pressure gain can then be calculated from the assumption of constant total pressure. This is obviously a simplification in most cases, since, for instance, the air close to the ceiling moves slower than mean velocity when traffic is moving freely.

\subsubsection{Tunnel junctions}

For normal duct flow, loss coefficients in branching components can be calculated by formulae fetched from HVAC handbooks [Miller 1978]. The coefficients depend on flow velocities and on duct geometry, especially angles between branches. In road tunnel junctions, angles between branches tend to be more acute than in ventilation ductwork, which makes the application of duct formulae extra uncertain.

In the computer program, duct formulae are used for converging junctions, and losses are related to the air speed in the common branch. For diverging junctions, explicit loss coefficients have to be supplied by the user, and losses are related to the highest air speed in any of the three branches. In both cases, resulting air flows should be checked carefully to ensure that calculated losses are reasonable.

\subsubsection{Tunnel portals}

Wind pressure is a factor of importance especially for longitudinally ventilated tunnels, but also for all systems aiming at no emission through the portals. The resulting force depends on the difference between the atmospheric overpressure at the windward side and the underpressure at the other side (this difference must be given to the computer program). Due to the distance between the two portals, there is usually a considerable damping of the influence of gusts of wind. Naturally, the surroundings of the portals have a dominating influence, and to evaluate this factor, scale model wind tunnel tests (also simulating the ground boundary layer) are most valuable. In each specific case, the size of wind force that should be used in the design of the ventilation is, to a large extent, dependent on the acceptable risk of having to close the tunnel.

\subsection{Pollution concentrations}

The pollution concentrations in a tunnel depend on air flow in the tunnel, supply and exhaust of ventilation air and emission rate along the tunnel. The emission rate depends on the stock of vehicles, the slope of the tunnel, and weather conditions. The pollutants most discussed are CO, NOx, and smoke, and it may be noted that their emissions have different characteristics relative to for instance vehicle speed.

The differential equations describing the concentrations can be integrated by the program with time varying boundary conditions. The results will describe the concentrations along the tunnel as 
depending on initial pollution concentration and on varying tunnel air flow, fresh air supply, exhaust rate of vitiated air, and, of course, emission rate. However, since the time variations of driving functions are relatively slow, dynamic studies are mostly not required, and the program has so far been used to calculate steady state conditions at selected points in time.

\subsection{Inventory of models}

Table 1 shows the central models that have been developed for the program and their respective parameters.

Table 1: NMF Models in Tunnel Ventilation Library

\begin{tabular}{|l|l|l|}
\hline $\begin{array}{l}\text { Model } \\
\text { name }\end{array}$ & Function & Parameters \\
\hline XtEntry & Entry portal & Tunnel area, loss coefficient \\
\hline XtExit & Exit portal & Ditto \\
\hline XtBrchOf & Exit junction & $\begin{array}{l}\text { Tunnel areas in three branches; } \\
\text { two loss coefficients }\end{array}$ \\
\hline XtBrchOn & Entry junction & $\begin{array}{l}\text { Tunnel areas in three branches; } \\
\text { radius of point between joining branches; } \\
\text { two parameters to calculate loss coefficients }\end{array}$ \\
\hline XtAirExh & Air exhaust & Tunnel area, loss coefficient \\
\hline XtAirSup & Air supply & Ditto \\
\hline XtTunnel & Undivided tunnel & $\begin{array}{l}\text { Friction factor; } \\
\text { Tunnel area, hydraulic diameter plus } \\
\text { loss coefficients at area changes; } \\
\text { jet fan area, momentum \& efficiency; } \\
\text { vehicle speed zones }\end{array}$ \\
\hline
\end{tabular}

Vehicle flows and speeds, ventilation air flows, fan speeds, and emission rates are given as time varying boundary data.

To give a flavour of the NMF code, the model XtEntry is presented in Figure 1. 


\section{CONTINUOUS_MODEL XtEntry}

ABSTRACT "Tunnel entry;

one-dir 2-part traffic, bi-dir air w TWO fractions" $/ *$
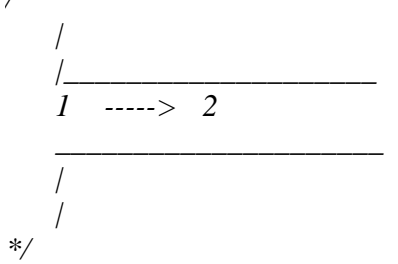

\section{EQUATIONS}

/*ambient conditions */

$\mathrm{P} 1=\mathrm{PAmb}+\mathrm{PWind}$;

/* effective density */

IF VFAir $1>0$ THEN

Rho := 1 / GASCON * $(101325+$ P1) / (T1 - ABS_ZERO $)$; $M:=$ VFAir1 * Rho ;

ELSE

Rho := $1 /$ GASCON * $(101325+$ P2) / (T2 - ABS_ZERO);

$M:=$ VFAir2 * Rho ;

END_IF ;

/* conserve mass flow */

VFAir1 * $(101325+$ P1 $)=$ VFAir2 * $(101325+$ P2 $)$;

/* air velocity */

VAir $=($ VFAir1 + VFAir2) / 2 / aTun ;

/* energy equation */

$\mathrm{P} 1=\mathrm{P} 2+$

IF M > 0 THEN Rho / 2 * $(1+$ Ki) * Vair**2

ELSE 0

END_IF ;

/* convected heat through tunnel */

$\mathrm{Q}=\mathrm{IF} \mathrm{M}>0$ THEN CP_AIR_M ${ }^{*} \mathrm{~T} 1{ }^{*} \mathrm{M}$

ELSE CP_AIR_M ${ }^{*} T 2 * M$

END_IF ;

/* fraction transported through tunnel */

$\mathrm{XCOf}=\mathrm{IF} M>0$ THEN VFAir1 ${ }^{*} \mathrm{XCO} 1$

ELSE VFAir $2 *$ XCO2

END_IF ;

$X N O 2 f=I F M>0$ THEN VFAir1 * XNO21

ELSE VFAir2 * XNO22

END_IF ;

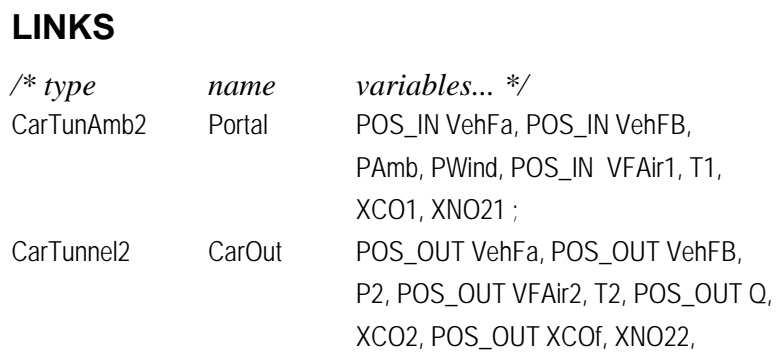

\section{VARIABLES}

$\begin{array}{llll}\text { /*type } & \text { name } & \text { role } & \text { description */ } \\ \text { MassFlow } & \text { M } & \text { LOC } & \text { "mass flow [kg/s]" } \\ \text { Pressure } & \text { P1 } & \text { OUT } & \text { "tunnel entry pressure" } \\ \text { Pressure } & \text { P2 } & \text { OUT } & \text { "terminal 2 pressure" } \\ \text { Pressure } & \text { Pamb } & \text { IN } & \text { "ambient static pressure" } \\ \text { Pressure } & \text { Pwind } & \text { IN } & \text { "wind pressure" } \\ \text { HeatFlux_M } & \text { Q } & \text { OUT } & \text { "heat moved by massflow" } \\ \text { Density } & \text { Rho } & \text { LOC } & \text { "density of tunnel air" } \\ \text { Temp } & \text { T1 } & \text { IN } & \text { "Temperature of neighbor 1" } \\ \text { Temp } & \text { T2 } & \text { IN } & \text { "Temperature of neighbor 2" } \\ \text { Velocity } & \text { Vair } & \text { OUT } & \text { "air speed [m/s]" } \\ \text { NumFlow_h } & \text { VehFA } & \text { IN } & \text { "vehicle flow small [1/h]" } \\ \text { NumFlow_h } & \text { VehFB } & \text { IN } & \text { "vehicle flow big [1/h]" } \\ \text { VolFlow } & \text { VFAir1 } & \text { IN } & \text { "air volume flow 1 [m3/s]" } \\ \text { VolFlow } & \text { VFAir2 } & \text { OUT } & \text { "air volume flow 2 [m3/s]" } \\ \text { VolFract_y } & \text { XCO1 } & \text { IN } & \text { "fraction CO of neighbor 1" } \\ \text { VolFract_y } & \text { XCO2 } & \text { IN } & \text { "fraction CO of neighbor 2" } \\ \text { FractFlow_y } & \text { XCOf } & \text { OUT } & \text { "fract CO moved by flow" } \\ \text { VolFract_n } & \text { XNO21 } & \text { IN } & \text { "fraction NO2 of neighbor 1" } \\ \text { VolFract_n } & \text { XNO22 } & \text { IN } & \text { "fraction of neighbor 2" } \\ \text { FractFlow_n } & \text { XNO2f } & \text { OUT } & \text { "fract NO2 moved by flow" } \\ \text { PARAMETERS } & & & \end{array}$

/*type name role defmin max description */

/* easy access parameters */

area aTun S_P 50 SMALL BIG "cross section area [m2]"

factor ki S P 1 SMALL BIG "Loss coeff for inlet"

\section{END MODEL}

Figure 1. Sample NMF code

\subsection{An Example}

The layout of a fairly complicated tunnel system, simulated by the program, is shown in Figures 2 and 3 . The example is fetched from the design of a planned ring road system, encircling the central built- 


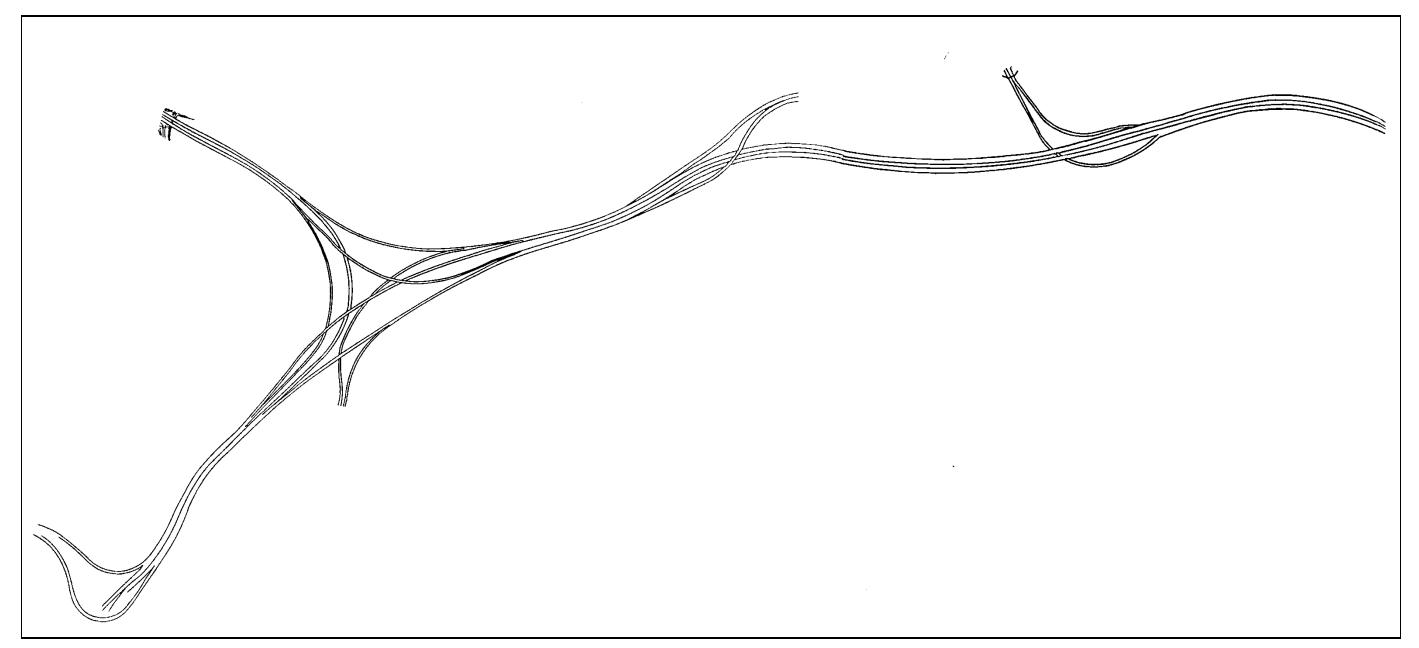

Figure 2: Map of sample tunnel system

Some key data of the simulated system are given in table 2 .

Table 2: Key data for sample system

\begin{tabular}{|l|l|}
\hline Number of components & 71 \\
\hline Number of equations in system matrix & 631 \\
\hline Total number of variables in components & 2705 \\
\hline Calculation time on a 90 Mhz Pentium & $66 \mathrm{~s}$ \\
\hline
\end{tabular}

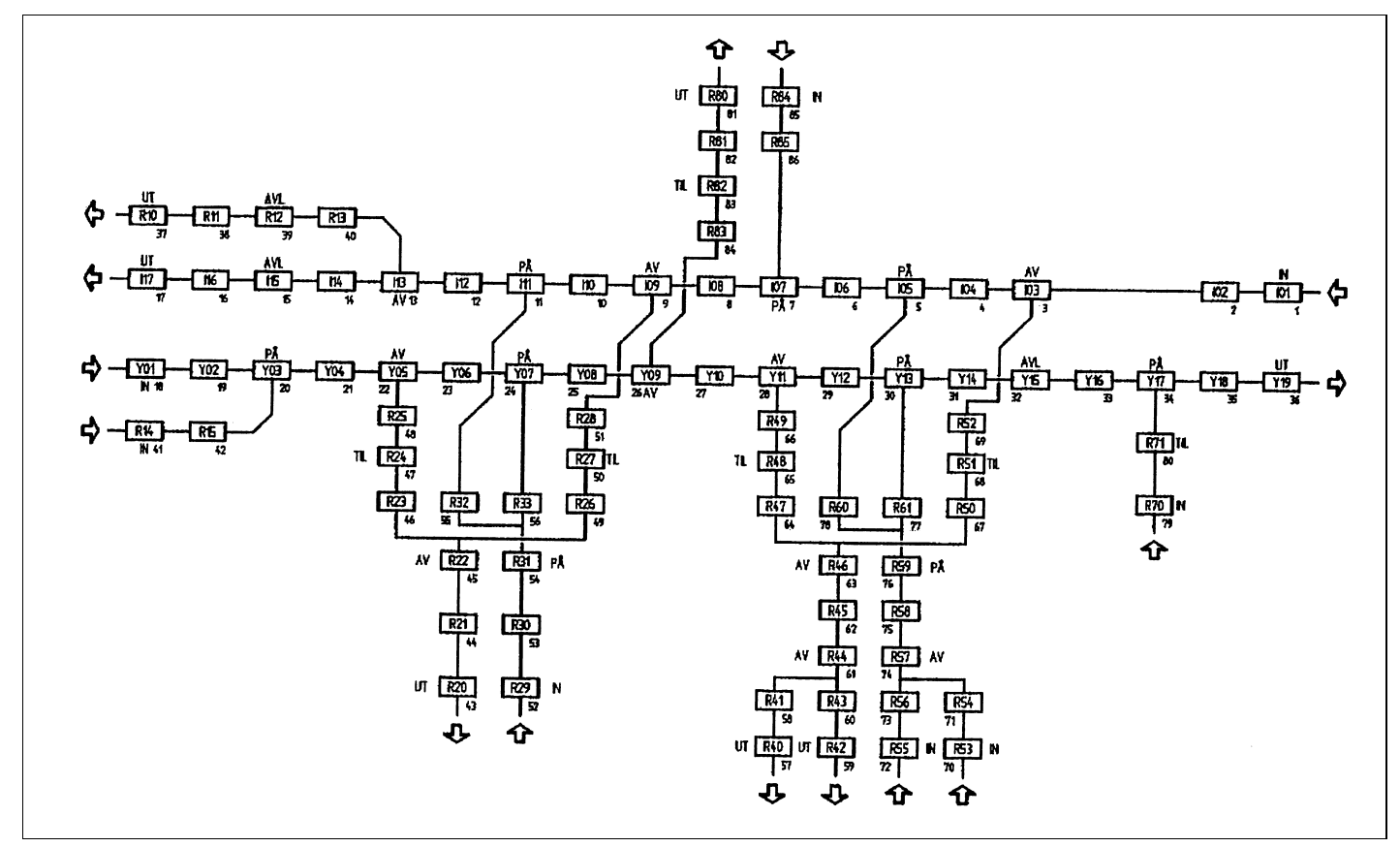

Figure 3: System schema showing module decomposition 


\section{Measurements in the "Söderledstunneln"}

\subsection{The tunnel}

Söderledstunneln is a tunnel in central Stockholm, $1500 \mathrm{~m}$ long. It is running in north-south direction and consists of two separated tubes, one for northgoing traffic and one for southgoing, each with two lanes. The layout of the tunnel is schematically shown in Figure 4. Each tube is longitudically ventilated with momentum fans to assist when the traffic is slow moving or in case of fire. The tunnel is equipped with three ventilation shafts for exhausting polluted air through chimneys, two located $500 \mathrm{~m}$ into the tunnel from the north end (one in the north going and one in the southgoing tube) and one in the southern end of the southgoing tunnel. No ventilation chimney was accepted at the northern end of the tunnel. Instead the wall between the two tunnel tubes has openings close to the northern end to allow air from the northgoing tube to be entrained into the southgoing tube, with the help of momentum fans. Due to its downtown location, the tunnel is much used. Figure 5 shows normal traffic flow rates and Figure 6 mean velocities for the traffic in the southern part of the

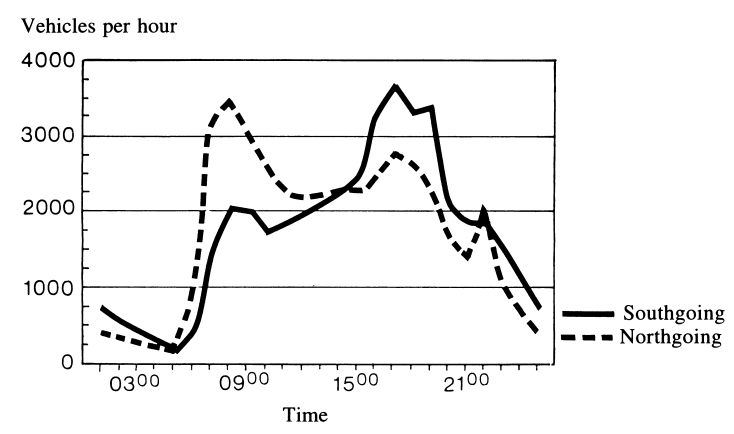

Figure 5: Normal traffic flow rates

northgoing tunnel tube [Johansson 1996]. The northgoing traffic typically consists of $96 \%$ cars and vans, $3 \%$ lorries and $1 \%$ buses.

Normally, there is no need to use the momentum fans, but the air flow is driven by the piston force of the traffic. The momentum fans are started when the concentration of pollutants in the tunnel air is high. The exhaust fans are also controlled by the degree of pollution in the tunnel air, and are started when it is necessary to protect the environment of the tunnel portals.

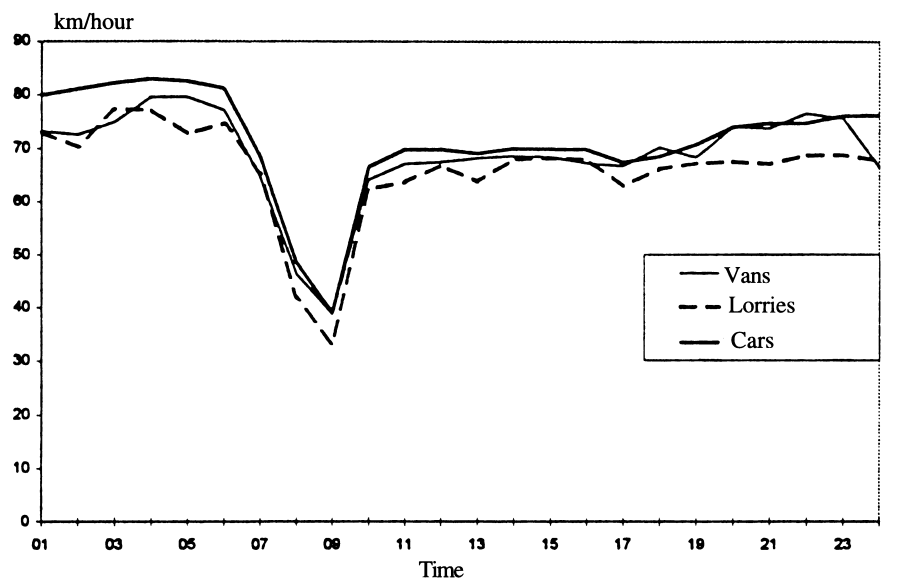

Figure 6: Mean velocities 


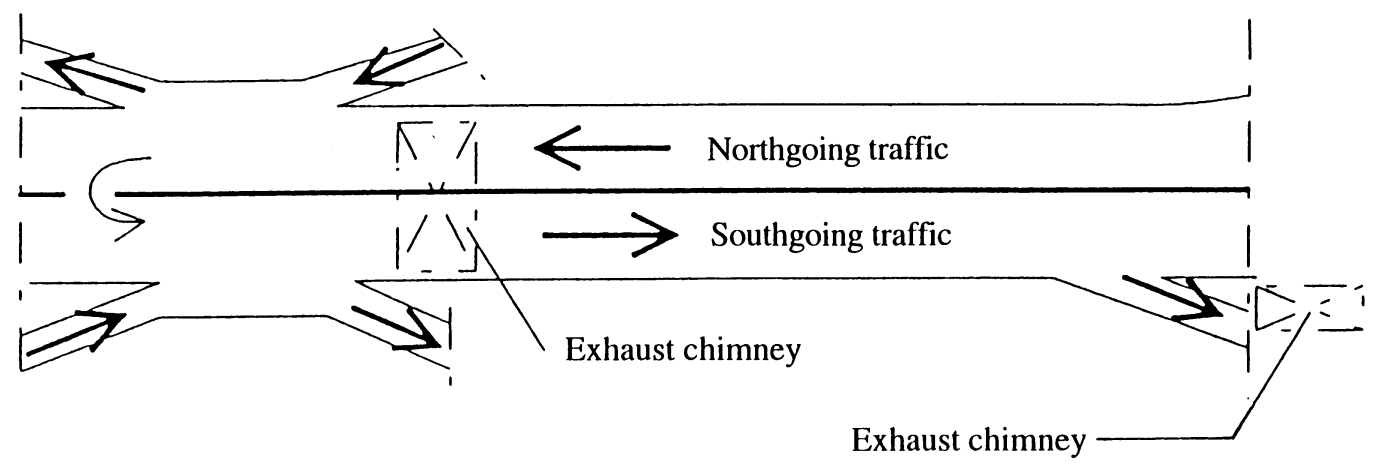

Figure 4: Layout of studied section of "Söderledstunneln"

The southern part of the northgoing tunnel tube is $1000 \mathrm{~m}$ long with no dividings. This part was selected for the tracer gas measurements.

\subsection{Test Methodology}

The tracer gas $\left(\mathrm{SF}_{6}\right)$ was injected into the tunnel air close to the opening and a distance of $940 \mathrm{~m}$ could be allowed for mixing of the gas and the air (see Figure 7 ). All tests were made with traffic in the tunnel, which of course enhanced the mixing. When the momentum fans were running, they increased the mixing further. It is interesting to note, that, in spite of these mixing enhancing factors and a mixing length of about 100 tunnel tube diameters, the gas concentration in the plane of

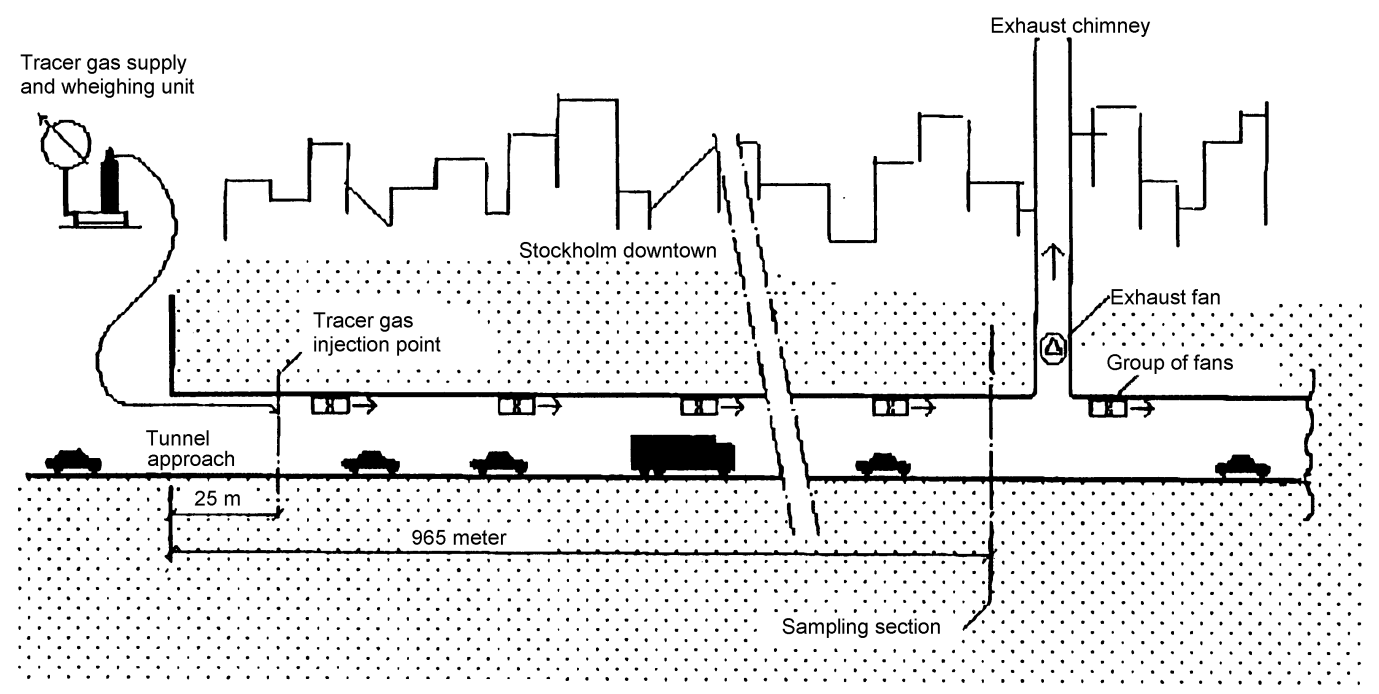

Figure 7: Longitudinal section through measured part of tunnel 


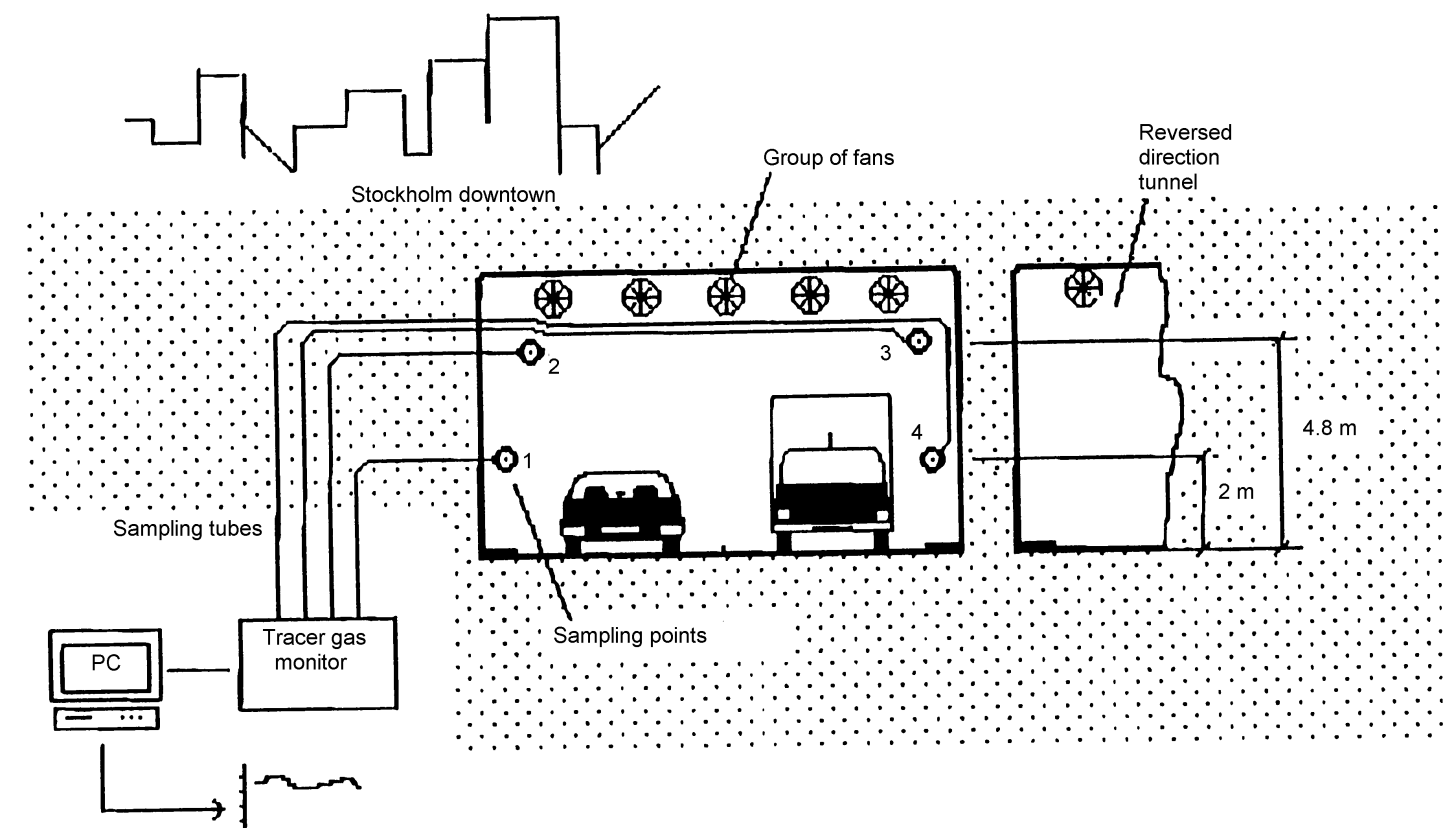

Figure 8: Location of measuring points in cross section

measurement was not completely homogeneous. This was shown by comparisons between measured values, taken in four different positions (see Figure 8).

The tracer gas was supplied from a pressurized container by means of a valve and a flow measuring device, which latter mainly was used for keeping the supply rate constant. The supplied amount and rate was measured by weighing the container and measuring the corresponding time with a stop watch. The injection point was located at a side wall, a little more than $1 \mathrm{~m}$ above the tunnel floor.

In the plane of measurement air was taken out to the analyzing equipment, which was located in a room beside the tunnel, through soft plastic tubes. From the start of tracer gas supply, there was first a time delay of several minutes before the tunnel air with tracer gas reached the test section, then a delay due to transport through the plastic tubes, and finally, a delay due to the time constant of the analyzing equipment. "Steady state" conditions, with a constant tracer gas concentration, was never reached. The recorded signal always fluctuated, and the concentration on which evaluation of air flow rate was based had to be estimated as a mean, when a "quasi steady" state had been established.

Tests were also made with fans running. There were then some unexpected problems. The first test day the exhaust fans didn't work. All fans were normally controlled from an office several kilometers from the tunnel and communication with the operator was via telephone. This caused some misunderstandings and delays. Uncertainty regarding which fans that actually were running meant that some tests could not be used.

\subsection{Test Results and Comparisons with Simulations}

Test were made at three occasions, December 1993, September 1994 and October 1994.

Measured air flow rates were, with no momentum fans running, in the range 270-330 $\mathrm{m}^{3} / \mathrm{s}$ (depending mainly on traffic conditions); with every second row of momentum fans runnning, 390-430 $\mathrm{m}^{3} / \mathrm{s}$; and with all momentum fans running, in the range $430-480 \mathrm{~m}^{3} / \mathrm{s}$. The measuremnts made in the afternoon of December 20, 1993, have been chosen for the comparisons with simulations. The reasons for this choice are: the measurements were made during a time of day when traffic flow rate and speed are rather constant (compare Figures 5 and 6, and table 4); the traffic was counted during this period. 
(Traffic counting was not available at the other occasions). The documentation of which fans that were running was also reliable for this period.

The results are shown in table 4 together with results of simulations. Input values (normal) for some central parameters to the simulations are given in table 3 . These values have been selected, based on previous experiences, and have not been fitted to the measured values.

Table 4 gives simulation results calculated with normal parameter values; some results, where parameters have been varied to illustrate sensitivity to parameter choices, are shown in table 5.

Table 3: Normal parameter values for air flow simulations

\begin{tabular}{|l|l|}
\hline Parameter description & Normal value \\
\hline Wall friction coefficient & 0.020 \\
\hline Cross section area $\left[^{2}\right.$ ], cars & 2.0 \\
Ditto, lorries and buses & 7.0 \\
\hline Vehicle drag coefficient, cars & 0.30 \\
Ditto, lorries and buses & 0.60 \\
\hline Fan efficiency [\%], all fans running & 50 \\
Ditto, every second row running & 60 \\
\hline
\end{tabular}

Table 4: Comparison between measured and calculated air flows

\begin{tabular}{|r|r|r|r|r|r|r|}
\hline $\begin{array}{r}\text { Measurement } \\
\text { number }\end{array}$ & $\begin{array}{r}\text { Time of } \\
\text { measurement }\end{array}$ & $\begin{array}{r}\text { Total } \\
\text { trafic flow } \\
{[\text { veh/h] }}\end{array}$ & $\begin{array}{r}\text { Exhaust } \\
\text { air flow } \\
{[\mathrm{m} 3 / \mathrm{s}]}\end{array}$ & $\begin{array}{r}\text { Momentum } \\
\text { fans running }\end{array}$ & $\begin{array}{r}\text { Calculated } \\
\text { air flow } \\
{[\mathrm{m} 3 / \mathrm{s}]}\end{array}$ & $\begin{array}{r}\text { Measured } \\
\text { air flow } \\
{[\mathrm{m} 3 / \mathrm{s}]}\end{array}$ \\
\hline 2 & $13: 15-13: 30$ & 2516 & 0 & none & 304 & 324 \\
\hline 6 & $15: 05-15: 25$ & 2576 & 0 & every 2nd row & 424 & 426 \\
\hline 14 & $15: 35-15: 55$ & 2572 & 0 & every row & 469 & 473 \\
\hline
\end{tabular}

As can bee seen from table 4, the differences between measured and calculated values are acceptable. 
Table 5: Influence of parameter changes on calculated air flows

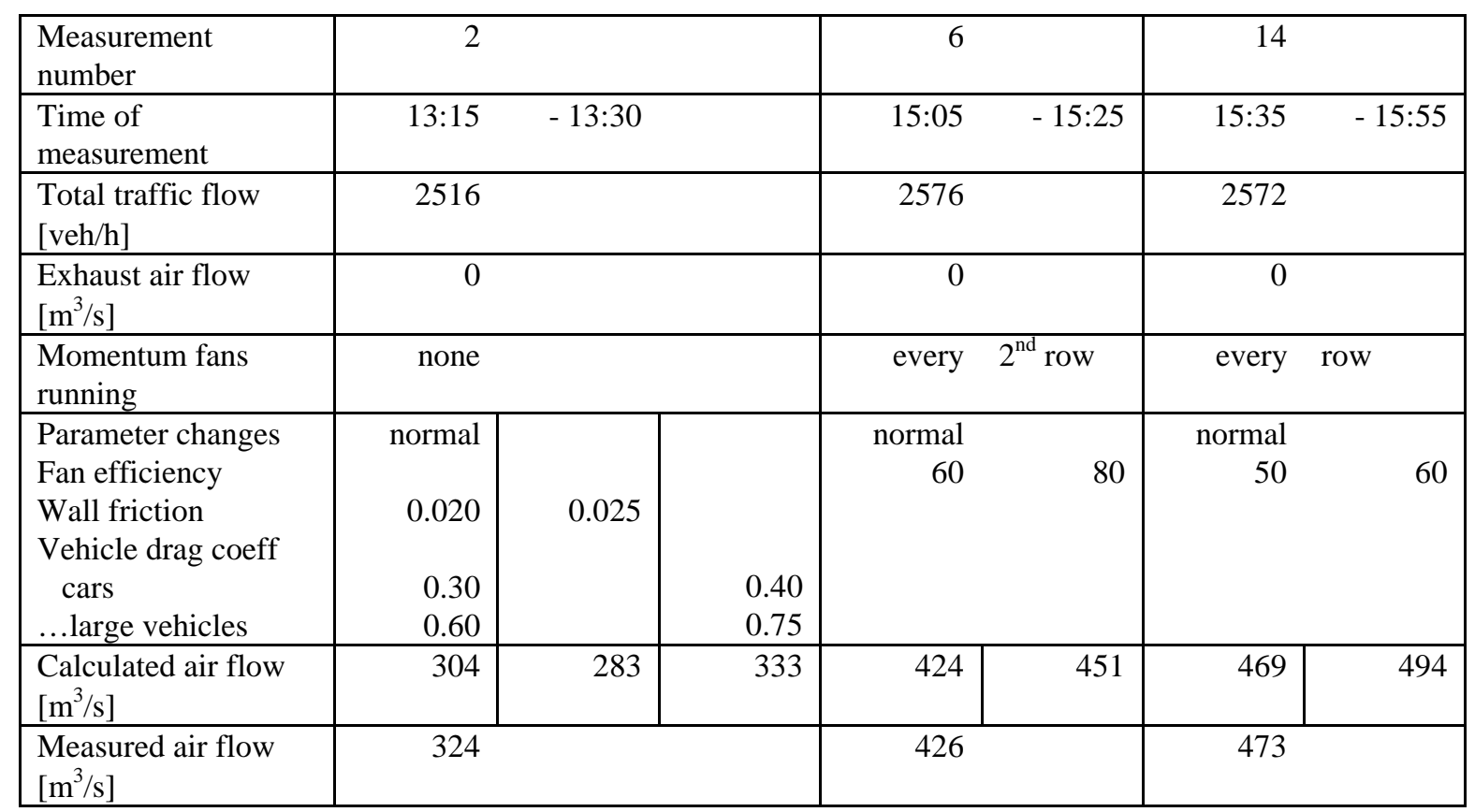

In this tunnel, the momentum fans are located in compact rows, of six fans each, in the tunnel ceiling. The distance between rows is rather short. These factors are the cause for the low efficiency assumed for the momentum fans, and also the cause for the higher value assumed, when only every second row is running.

\subsection{Simulation of the total tunnel air flow}

The first case in table 3 (no fans) is the normal case. Results of the simulation for this case are given in Figure 9. The simulations have been made assuming the same traffic flow rate in the southgoing tunnel as in the northgoing.

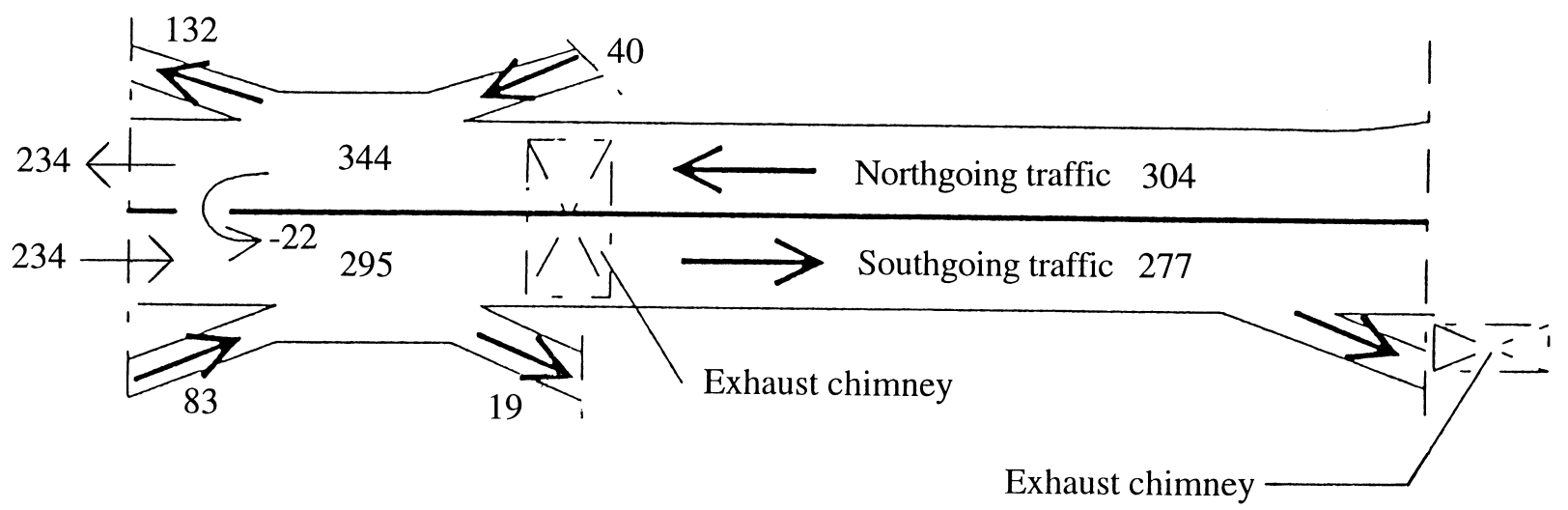

Figure 9: Calculated air flows $\left[\mathrm{m}^{3} / \mathrm{s}\right]$ for normal case (no fans running) 


\section{Discussion}

New simulation environments allow rapid generation of efficient application tools. The modular structure of these environments facilitates fast development and maintenance of programs based on equation based models. Component models formulated in the Neutral Model Format make the assumptions behind an application program easily accessible and understandable for the intended user group of consultant engineers. A general solver for differential-algebraic systems with algebraic loops allows handling of arbitrary tunnel networks. A program based on this principles has been developed. Additionally, a version to handle fires in road tunnels hass been prepared. Further work will aim at a graphical user interface.

Measurement of air flow rates have been made in a tunnel in central Stockholm. Measured and simulated values show good agreement.

\section{References}

Ackeret, J., Haerter, A., Stahel, M. (1961), “Die Lüftung der Autotunnel”, Mitteilung Nr 10, Institut für Strassenbau and der ETH, Zürich.

Johansson, C., P-Å. Johansson, L.Burman (1996), "Emissioner av kväveoxider och kolmonoxid från trafik - Analys av mätningar i Söderledstunneln", Institute of Applied Environmental Research, September 1996.

Kawamura, R., H. Ohashi, E. Inami, T. Ishidaki (1973), "Study on semi-transverse ventilation of automobile tunnels", First International Symposium on the Aerodynamics and Ventilation of Vehicle Tunnels, BHRA.

Malmström, T-G. (1980), “A Computer Program for Road Tunnel Ventilation”, Rockstore, Stockholm June 1980.

Miller, D.S. (1978), “Internal Flow Systems”, Volume 5, BHRA Fluid Engineering Series.

PIARC (1991), Committee on Road Tunnels, Report, XIXth World Road Congress, Marrakesh, September 1991.

Pursall, B., ., West, A. (1976), Induced ventilation in road tunnels - a theoretical and practical analysies. Second International Symposium on the aerodynamics and $v$ entilation of vehicle tunnels, BHRA.

Pursall, B., R., West, A., (1979), Induced ventilation in road tunnels - a comparison between fullscale and model studies. Third International Symposium on the aerodynamics and ventilation of vehicle tunnels. BHRA.

Sahlin, P., A. Bring (1991), "IDA Solver - A Tool for Building and Energy Systems Simulation", paper presented at Building Simulation '91, Nice, France 1991.

Sahlin, P., A.Bring, E.F.Sowell (1994), “The Neutral Model Format for Building Simulation”, Version 3.01, ITM report 1994:4. 